How to cite this article:

Benlahcene, A., Awang-Hashim, R., \& Kaur, A. (2020). Personal best goals: Do they mediate the relationship between teacher autonomy support and student engagement? Malaysian Journal of Learning \& Instruction, 17(1), 25-49. https://doi.org/10.32890/ mjli2020.17.1.2

\title{
Personal Best Goals: Do they Mediate the Relationship between Teacher Autonomy Support and Student Engagement? ${ }^{1}$ Abderrahim Benlahcene, ${ }^{2}$ Rosna Awang-Hashim \& ${ }^{3}$ Amrita Kaur \\ ${ }^{1-3}$ School of Education and Modern Languages, Universiti Utara Malaysia, Malaysia \\ Corresponding author: abderrahim_b@ahsgs.uum.edu.my
}

Received: $19 / 6 / 2019$ Revised: 28/9/019 Accepted: 10/12/2019 Published: 31/1/2020

\begin{abstract}
Purpose - The role of teacher autonomy support (TAS) is central to students' engagement. However, there is a scarcity of empirical evidence on the mediating role of personal best $(\mathrm{PB})$ goals between autonomy support and student engagement. Hence, in this research we examined the extent to which TAS could impact cognitive, behavioural and emotional engagement with the mediating role of PB goals among undergraduate students.
\end{abstract}

Methodology - A cross-sectional research design was applied. A total of 266 undergraduate students from a large government university located in northern Malaysia participated in this research. The Learning Climate Questionnaire (LCQ) and the Personal Best Scale were used to measure the students' perception of TAS and their PB goals respectively, while the Engagement Versus Disaffection with Learning measurement scale and the Metacognitive Strategies Questionnaire were used to collect data on cognitive, behavioural and emotional engagement. Structural Equation Modelling using AMOS 23 was adopted to test the hypothesized relationships.

Findings - The results of the study support our postulated model, showing that TAS is related with student engagement aspects through the full mediating role of PB goals. 
Significance - These results augment the present understanding of the self-determination theory motivation mediation model by highlighting that creating a conducive learning environment that facilitates self-determined behaviours among students will nurture PB goals and enhance engagement, which will be beneficial for teaching and learning processes in education.

Keywords: Autonomy support, personal best (PB) goals, student engagement, higher education.

\section{INTRODUCTION}

The significance of engagement is well documented in educational contexts, with strong links observed between student engagement and achievement at both elementary and tertiary levels (Maguire, Egan, Hyland, \& Maguire, 2016). In higher education, student engagement is primarily focused on the time and effort invested by institutions and students to attain the desired optimal learning experiences, academic achievement, as well as reputation and performance among institutions (Trowler \& Trowler, 2010). Sufficient student engagement at university level has emerged as one of the most pressing issues for higher education in the $21 \mathrm{st}$ century, as this concept relates to quality assurance and enhancement agendas worldwide (Healey, Flint, \& Harrington, 2014). Healey et al. (2014) argued that student engagement is a holistic and complex phenomenon that needs much more research to become a useful platform for improving learning in higher education. In this sense, it has become vital to identify the extent to which students are engaged and the effective educational practices that encourage engagement (Abdul Rahim \& Lee 2017; Zepke, 2017).

In recent years, the subject of student engagement has gained much attention across higher education institutions worldwide, which has led to the introduction of initiatives to improve educational quality through strengthening student engagement. Among them are the establishment of the Centre for Community College Student Engagement (CCCSE) in 2001 at the University of Texas, USA (CCCSE, 2019), and the Centre for Higher Education Research and Information (CHERI), which has focused on effective strategies to boost academic engagement within higher educational institutions in the UK context (Little, Locke, Scesa, \& Williams, 2009). 
Additionally, over the 70 years of studies on academic engagement, researchers have established various surveys to measure behaviours related with the quality of effort and participation of higher education institutions to produce learning activities that vitalize academic engagement (Zepke, 2017). The most influential example of these surveys is the "National Survey of Student Engagement" (NSSE), which was subsequently adopted by most developed higher education systems around the world (Macfarlane \& Tomlinson, 2017). Currently, the relevance of student engagement in higher education remains undisputed and issues related to this concept remain high on the agendas of higher institutions, especially with regards to investigating the predictors of engagement (Zepke, 2017).

Higher education institutions in Malaysia are not exempted from this trend of seeking effective ways to enhance student engagement. For instance, Yusoff (2012) implemented the National Survey of Student Engagement (NSSE) to explore and better understand the processes of teaching and learning that enhance students' engagement in higher education. Similarly, Md Jaafar, Awang-Hashim, and Tengku Ariffin (2012) developed the Malaysian University Student Learning Involvement Scale (MUSLIS) to better understand student engagement within Malaysian institutional contexts, as well as to discover the activities that students participated in, and how those activities enriched students' academic development. According to its National Education Blueprint (2015-2025), Malaysia aspires to develop the quality of higher education by strengthening the levels of engagement and interactivity among students (Ministry of Higher Education, 2016). Undeniably, the phenomenon of disengagement still exists among Malaysian undergraduates due to a lack of in-depth understanding of the dynamics of student engagement, which in turn prevents educational institutions from applying practical solutions to relevant areas (Abdullah, Teoh, Roslan, \& Uli, 2015). Salleh, Desa, and Tuit (2013) argue that student engagement is not even a common variable in studies within Malaysian higher educational contexts. Furthermore, most of the empirical studies on this construct have been restricted to students in the elementary, middle, and high school contexts (e.g., Awang-Hashim, Kaur, \& Noman, 2015; Awang-Hashim \& Sani, 2008; Sahil \& Awang-Hashim, 2011). Acknowledging the fact that student engagement remains sparsely explored in Malaysian higher education, the current study therefore proposes a robust literature-based model to investigate the extent 
to which teacher autonomy support (TAS) (Deci \& Ryan, 2000) is related to personal best (PB) goals and three outcomes of academic engagement. Specifically, we consider how students' perceptions of TAS is linked to PB goals, and how these goals, in turn, foster students' behavioural, cognitive and emotional engagement.

Previous studies have asserted that both PB goals and student engagement have high associations with optimal educational outcomes such as motivation, effort and overall academic performance (Martin \& Elliot, 2015; Zepke, 2017). This study sought to extend the knowledge regarding the association of these constructs with TAS. It is well known that TAS in learning settings predicts student engagement because TAS is concerned with autonomous behaviours which are self-regulated and undergirded by psychological freedom and self-choice towards learning (Jang, Reeve, \& Deci, 2010; Yuan \& Kim, 2018). Similarly, Collie, Martin, Papworth and Ginns (2015) found that PB goals mediated the association between personal relationship with peers, teachers and parents, and academic engagement. However, empirically, research on the mediating role of PB type of growth goals between TAS and student engagement is still in its infancy, and has yet to examine the association between TAS and PB goals, or how TAS and PB goals explain student engagement when integrated into the same model.

Hence, to contribute to the existing literature on associations of the study variables, we employed structural equation modelling (SEM) to examine the structural relationships between undergraduates' perceptions of TAS, PB goals, and student engagement simultaneously. The study will make a significant contribution to current understanding on the distinctive nexus that TAS and PB goals have with student engagement. It will also shed new light on the significant association that PB goals have with student engagement in the presence of TAS concurrently. This is important for providing a complete understanding regarding the relevance of less explored growth goals, in terms of PB goals. Besides the empirical basis of our investigation, there is also a theoretical rationale. In the current research, we emphasize on self-determination theory (SDT) (Deci \& Ryan, 2008) as an underpinning theory that provides a suitable framework upon which TAS, PB goals, and student engagement maybe associated. 


\section{THEORETICAL FRAMEWORK}

According to SDT, autonomy supportive teaching styles enhance optimal functioning among students, such as autonomous motivation, psychological well-being, learning, engagement and personal growth (Gagné, 2003; Reeve, 2012). Concretely speaking, when teachers provide autonomy support in their classroom, the students are more likely to have their basic psychological needs for autonomy, competence and relatedness fulfilled, which promotes high-quality types of engagement in classroom activities (Jang, Reeve, \& Halusic, 2016; Núñez \& León, 2019). From the SDT perspective, TAS is defined as the degree to which the teachers take the target students' perspective and act in ways that enhance selfchoice, self-initiation, volitional behaviours, sense of psychological freedom, and self-endorsement of the undertaking behaviours (Deci \& Ryan, 2000; Niemiec \& Ryan, 2009). In the same vein, TAS contains a variety of teacher behaviours where efficacy has been evidenced in SDT research, such as instilling a sense of self-choice and involvement (Assor, Kaplan, \& Roth, 2002; Reeve \& Halusic, 2009 ), providing rationale and clarifying the value and importance of the studied material (Reeve, 2009), enabling students' expression of negative emotions and doubts regarding teaching and learning processes (Assor et al., 2002), facilitating personal initiative and using noncontrolling language (Deci \& Ryan, 2000; Reeve, 2006), and allowing students to work at their own pace and implementing teaching methods based on their interest (Hang, Kaur, \& Nur, 2017; Jang et al., 2016).

SDT asserts the hypothesized relationship between TAS and PB gaols. This is rooted in the idea that TAS enhances students' sense of volition, self-choice, and self-determined behaviours in their learning activities (Benita, Roth, \& Deci, 2014). When students experience perceived TAS in the classroom, they are more likely to be in a learning environment that provides that sense of volitional control over their academic growth, because TAS embraces the perception that students are the origin of their own actions, which makes them experience the choice and freedom to pursue their PB goals. Additionally, PB goals are self-referenced, self-determined, and created by the students about their own academic progress and outcomes (Collie \& Martin, 2015). Thus, PB goals feature the sense of volition and choice which are central to TAS (Collie et al., 2015; Ryan \& Deci, 2000). Therefore, TAS functions as a central mechanism in enriching PB goals. 
Furthermore, SDT posits that an individual's engagement in behaviours and various learning activities is undergirded by two primary qualities of motivation, namely autonomous and controlled motivation. Currently, it is contended that these types of motivational reasons can affect the way students regulate the setting and pursuit of their adopted goals (Vansteenkiste, Lens, Elliot, Soenens, \& Mouratidis, 2014). The critical point is that the goals that students hold and pursue can be distinguished based on the guidance of autonomous or controlled motivational reasons (Benita et al., 2014). Hence, given the self-reference and self-determination features of PB goals, we suggest that autonomous motivational reasons which originate from the contexts that embrace TAS are highly pertinent factors for strengthening students' PB goals. Therefore, there are grounds to consider SDT as an informative theory for investigating and uncovering the relationship between TAS and students' PB goals.

In addition, SDT is of significance in understanding how TAS and PB goals may enhance and facilitate student engagement. When students experience TAS, they are expected to embrace the sense of self-direction and self-determination during their activities (PB goals), which in turn would predict positive educational outcomes in terms of a high quality of academic engagement (Benita et al., 2014; Reeve, 2012). Therefore, given the psychological nature of TAS and PB goals, where both are concerned with the issue of "self-determination", it is likely that these constructs will work in alignment to predict student engagement. Taken together, there are several grounds to consider SDT as a theoretical foundation for understanding and supporting the links between the variables under investigation in the current study.

\section{LITERATURE REVIEW}

\section{Personal Best (PB) Goals}

In the educational realm, goals refer to the purpose and meaning of students' actions and behaviours; also, goals are considered as a crucial factor that explains the motivational reasons behind activities in different situations (Maehr, 2001). The existing literature on goals is predominantly focused on the classic dichotomous-mastery and performance achievement goals (e.g., Elliot, Murayama, \& Pekrun, 
2011; Maehr, 2001). Mastery goals are self-improvement and selfreference to master specific tasks, whereas performance goals are attempts to show one's higher competence and performance in comparison to others (Ames, 1992; Maehr, 2001). However, PB goals have recently emerged as a focal point of growth goals as they are a positive blend of both mastery and performance orientations. This is so because PB goals reflect on self-reference and selfimprovement (mastery goals) as well as (self) competition as the students compete with their own previous best (performance goals) (Martin, 2012).

PB goals are self-based goals which emphasize on outperforming one's previous best and efforts; and success refers to doing better than previous performance and exceeding previous outcomes (Martin, 2012). The role that PB goals play in academic outcomes has been attested by previous research such as student engagement (Martin \& Elliot, 2015), academic achievement (Martin, Collie, Mok, \& McInerney, 2016), and task accomplishment (Martin \& Liem, 2010). Furthermore, previous studies on PB goals have revealed that these goals explain variance above and beyond the classic goals in the prediction of educational outcomes (e.g., Martin \& Elliot, 2015; Yu \& Martin, 2014), which suggest that PB goals function differently from mastery and performance goals.

TAS has been found to produce high-quality learning, personal growth, and students' autonomous motivation. It encourages students' ability to set their own goals and expand their efforts in implementing the strategies to attain set goals (Benita et al., 2014). Moreover, students' goals are more likely to be achieved when learning contexts adequately provide TAS for them to make their own choices and initiatives towards goals adoption and learning activities in general (Collie \& Martin, 2015). A number of empirical studies have asserted the relevance of TAS in the goals that students adopt (e.g., Benita, Shane, Elgali, \& Roth, 2017; Ciani, Sheldon, Hilpert, \& Easter, 2011; Collie \& Martin, 2015). However, no study so far has addressed the association of TAS with PB goals, either in the educational domain or in the others domains. Little is known how TAS, which is characterized by a great focus on self and volition, relate to PB goals. Hence, the current investigation is warranted as it would contribute towards an enhanced understanding of associations between TAS and PB. 


\section{Student Engagement}

Student engagement is a multidimensional construct that is generally concerned with behavioural, emotional and cognitive components (Fredricks, Blumenfeld, \& Paris, 2004). The behavioural component of engagement is defined as the actions that students undertake towards involvement and participation in classroom and extracurricular activities. Emotional engagement refers to the affective reactions that reflect students' emotional state during classroom activities, such as happiness, enjoyment, boredom, and anxiety, while cognitive engagement refers to the psychological investment and cognitive effort put towards a deeper comprehension and mastery of the necessary knowledge and skills. Student engagement is considered as the key factor that contributes to academic success in terms of short term (e.g., grades and achievement) and long term (e.g., attendance and academic resilience) benefits (Skinner, Kindermann, $\&$ Furrer, 2009). Students who experience engagement are more likely to excel in critical thinking and acquiring concrete knowledge and skills. They also report improved self-management (Ko, Park, Yu, Kim, \& Kim, 2016) and academic achievement (Hanita \& Azman, 2018; Heng, 2014). Additionally, research suggests that a high level of student engagement enhances retention at all levels (Zepke, 2017).

Studies have reported that TAS vitalizes students to be more autonomous in their undertaking of learning activities, as well as enhances their engagement. TAS is characterized by non-threatening classrooms and instruction that promote a sense of internal locus of causality, psychological freedom, volition, and full self-choice in respect to students' learning activities (Jang et al., 2010), which subsequently leads to better engagement (Hospel \& Galand, 2016). Similarly, it is well known that PB goals are associated positively with the three components of academic engagement (behavioural, emotional, and cognitive) (Martin et al., 2016). When students employ PB goals that mainly focus on competing with their previous best performance, they are likely to be involved in academic tasks to meet their self-improvement goals and to adopt behaviours which are more conducive to their personal growth and excellence, such as academic engagement (Martin \& Elliot, 2015). 


\section{THE PRESENT RESEARCH}

The current study aimed to examine the links between TAS and PB goals and understand further how these constructs work concurrently to predict behavioural, emotional, and cognitive engagement within the framework of an integrated model, among students in higher education. Thus, drawing upon empirical evidence and the theoretical premises of SDT, a hypothesized model of mediation was presented, whereby TAS could predict PB goals, which in turn, would predict students' engagement. In the current study, we tested the following hypotheses: (1) perceived TAS would positively predict students' engagement; and (2) TAS would indirectly predict students' engagement through PB goals.

\section{METHODOLOGY}

\section{Research Design}

The study employed a cross-sectional research design in which data were collected at one point of time to provide a precise picture of relationships that might exist among the variables being examined, and due to dependence on probability theory to address the postulated hypotheses statistically (Creswell, 2012).

\section{Participants}

The participants were 266 undergraduates from a large government university located in northern Malaysia. The students were enrolled in the College of Law, Government \& International Studies (19.5 $\%$ ), College of Business (72.5\%), and College of Arts \& Sciences $(8 \%)$. Participating students were 223 females $(83.8 \%)$ and 43 males $(16.2 \%)$, aged between 18 to 26 years $(M=21.46$ years; $S D$ $=1.22$ years $) .160(60.2 \%)$ students were enrolled in the first year, $58(21.8 \%)$ in the second year, and $48(18 \%)$ in the third year of university. With regards to ethnicity, $211(79.3 \%)$ of the students were Malay, 33 (12.4\%) were Chinese, and 22 (8.3\%) were Indian.

\section{Procedure}

Institutional permission was obtained prior to data collection. Data was collected during class by the students' own lecturers. However, 
the primary researcher was in the classroom to respond to any queries. The students were given the reasons and purpose of this study, and were informed that their participation was voluntary and confidential. They were asked to indicate their perceived autonomy support from their instructors, standards of their PB goals and engagement in reference to various courses that they were pursuing. The survey took approximately 10 to 20 minutes to complete.

\section{Measures}

Three scales were used to measure the proposed variables. The students rated all items using a 7-point Likert scale. The scale ranged from 1 (not at all true) to 7 (very true). The descriptive statistics, reliability value, and factor loadings for all the measurement scales appear in Table 1.

\section{Autonomy Support}

To measure students' perceptions of their perceived TAS, three items from the Learning Climate Questionnaire (LCQ) (Williams $\&$ Deci, 1996) were adopted with minor changes to suit the context of the current research. The three items were presented using the stem, "In my class..." followed by the item, e.g., "...I feel that my teacher provides me with choices and options". Previous studies have reported a Cronbach's alpha of .89 for the scale (e.g., Jang, Kim, \& Reeve, 2012).

\section{PB Goals}

To measure the students' standards of personal best (PB) goals, the four items from the Personal Best Scale (Martin \& Liem, 2010) were used. These items were presented using the stem, "In my class..." followed by the item, e.g., "... when I do my work, I try to do the best that I've ever done". A Cronbach's alpha of .88 has been reported in previous studies (e.g., Martin \& Liem, 2010).

\section{Student Engagement}

To measure the three dimensions of student engagement, the behavioural engagement ( 3 items) and emotional engagement (3 items) subscales of the Engagement Versus Disaffection with Learning measurement scale (Skinner et al., 2009) were employed. 
To assess cognitive engagement, the learning strategy items (4 items) from the Metacognitive Strategies Questionnaire (Wolters, 2004) were used. We employed this scale particularly because it conceptualizes cognitive engagement as elaboration-based learning strategies. Furthermore, previous research has revealed that the items of the metacognitive self-regulatory strategies subscale overloaded on the behavioural factor, which might lead to multicollinearity (see Reeve, 2013). The ten (10) items used the stem "In my class..." followed by the item, e.g., " ... I try hard to do well" for behavioural engagement; "... I enjoy learning new things" for emotional engagement; and "... when I study, I try to connect what I am learning with my own experiences" for cognitive engagement. Previous studies have reported Cronbach's alpha of $.87, .91$, and .72 for the behavioural, emotional, and cognitive subscales respectively (e.g., Reeve, 2013).

\section{DATA ANALYSIS}

All the analyses were performed using the SPSS 25 and AMOS 23 statistical packages. First, the data were checked for the presence of outliers and missing values using SPSS 25. Next, psychometric analyses (see Table 1) were performed to examine the distributional properties for each variable using descriptive statistics, internal consistency (Cronbach's $\alpha$ ), skewness and kurtosis. Furthermore, confirmatory factor analysis (CFA) was carried out to address the instruments' factor structure underlying the hypothesized model. The links between the variables under examination were calculated by Pearson correlation (see Table 2). The potential differences in students' engagement caused by gender, race, and educational levels were explored by $t$-test and ANOVA.

Structural equation modelling (SEM) using AMOS 23 was conducted to examine the relationship of TAS with the three engagement outcomes (behavioural, emotional and cognitive) through the mediation of PB goals. According to the mediating effect test procedure (Baron \& Kenny, 1986), we evaluated two structural models: first, the direct relationship model of TAS with behavioural, emotional, and cognitive engagement; second, to evaluate the indirect relationships, we added PB goals as a mediator between TAS and the three engagement outcomes, and inserted paths from TAS to PB goals and from PB goals to engagement outcomes (see 
Figure 1). Furthermore, to evaluate the statistical significance of the indirect effects, the bias-corrected bootstrap in AMOS 23 at a 95\% confidence interval was computed (MacKinnon, Lockwood, \& Williams, 2004).

To test goodness fit of the models, we carried out the fit indices tests with chi-square values, the comparative fit index (CFI), the standardized root-mean-square residual (SRMR), the incremental fit index (IFI), and the root-mean-square error of approximation (RMSEA) with $90 \%$ confidence interval (CI). Following the guidelines by $\mathrm{Hu}$ and Bentler (1999), the general cut-offs for accepting a model good fit are equal or $>0.95$ for CFI and IFI, equal to or $<0.06$ for RMSEA, and equal to or $<0.08$ for SRMR. However, given the difficulty to obtain a very good fit in testing models with multiple constructs, there was a general consensus for accepting the cut-off of CFI and IFI indices as equal or $>0.90$ (see Marsh, Hau, $\&$ Wen, 2004).

\section{RESULTS}

\section{Descriptive Statistics, Distribution and Reliability}

The mean, standard deviation, normality of the distribution (kurtosis, skewness), and internal consistency of the variables are exhibited in Table 1. Values of skewness (range $=-.49$ to -.23 ) and kurtosis (range $=-.56$ to .62$)$ suggested approximately normal distribution of the factors (Leech, Barrett, \& Morgan, 2005). The Cronbach's alpha values ranged from .69 to .83 , indicating satisfactory internal consistency (Hair, Anderson, Tatham, \& Black, 2006).

Table 1

Descriptive Statistics, Reliabilities and Factor Loadings

\begin{tabular}{llllll}
\hline Variables & $\begin{array}{l}\text { Mean } \\
(S D)\end{array}$ & Skewness & Kurtosis & $\begin{array}{l}\text { Reliability } \\
(\alpha)\end{array}$ & $\begin{array}{l}\text { Loading } \\
\text { range }\end{array}$ \\
\hline $\begin{array}{l}\text { 1. Autonomy } \\
\text { support }\end{array}$ & $4.99(.93)$ & -.23 & -.56 & .69 & $.64-.69$ \\
\begin{tabular}{l}
$\begin{array}{l}\text { 2. Personal } \\
\text { best goals }\end{array}$ \\
\hline
\end{tabular} & $5.74(.78)$ & -.49 & -.25 & .78 & $.49-.81$ \\
\hline
\end{tabular}

(continued) 


\begin{tabular}{llllll}
\hline Variables & $\begin{array}{l}\text { Mean } \\
(S D)\end{array}$ & Skewness & Kurtosis & $\begin{array}{l}\text { Reliability } \\
(\alpha)\end{array}$ & $\begin{array}{l}\text { Loading } \\
\text { range }\end{array}$ \\
\hline $\begin{array}{l}\text { 3. Behaviour- } \\
\text { al engage- } \\
\text { ment }\end{array}$ & $5.75(.81)$ & -.37 & -.34 & .77 & $.63-.81$ \\
$\begin{array}{l}\text { 4. Emotional } \\
\text { engage- } \\
\text { ment }\end{array}$ & $5.61(.83)$ & -.35 & -.20 & .69 & $.58-.73$ \\
$\begin{array}{l}\text { 5. Cognitive } \\
\text { engage- } \\
\text { ment }\end{array}$ & $5.58(.83)$ & -.46 & .62 & .83 & $.68-.81$ \\
\hline
\end{tabular}

$\mathrm{N}=266$

\section{Factor Analysis, Correlations and Individual Differences}

Factor Analysis

Prior to the structural equation modelling, a 5-factors confirmatory model analysis was computed. TAS, PB goals, and the three engagement dimensions (behavioural, emotional and cognitive) were allowed to be intercorrelated simultaneously for the assessment of the item loading on their respective latent factors. All items were used as the indicators of their respective latent factors. Model fit indices produced a well-fitting measurement model: $\chi 2=189.80$, $\mathrm{df}=108, \chi 2 / \mathrm{df}$ ratio $=1.75, \mathrm{CFI}=0.96, \mathrm{IFI}=0.96, \mathrm{RMSEA}(90 \%$ $\mathrm{CI})=0.053(0.041-0.066), \mathrm{SRMR}=0.05$. The results revealed that loadings ranged from .64 to .74 . Therefore, in conjunction with the above reported findings of normality of distribution and internal consistency, these results indicated a reasonable measurement basis to proceed with testing the correlations between the study variables and testing the hypothesized predictive model.

\section{Correlations and Individual Differences}

Table 2 summarizes the correlations for all the study variables. We found significant positive correlations among TAS, PB goals and the three aspects of student engagement (behavioural, emotional and cognitive), with a range of 0.45 to 0.71 . Furthermore, Table 2 shows that the correlations between the three student engagement aspects were positive and significant, with a range of 0.52 to 0.58 . 
Accordingly, these results provide preliminary support to proceed with statistical analyses in respect to the specified relationships in the hypothesized structural equation model (SEM).

In addition, we used t-test and ANOVA to test the potential gender, ethnicity and year of study differences in student engagement among the participants. The results revealed that there were no significant differences for gender $(\mathrm{t}=0.37, \mathrm{p}=0.709)$, year $(\mathrm{F}=.44, \mathrm{p}=0.816)$ and ethnicity $(\mathrm{F}=1.28, \mathrm{p}=0.281)$ in students' engagement.

Table 2

Pearson Correlations of the Study Variables

\begin{tabular}{llllll}
\hline Variable & 1 & 2 & 3 & 4 & 5 \\
\hline $\begin{array}{l}\text { 1. Autonomy support } \\
\begin{array}{l}\text { 2. Personal best } \\
\text { goals }\end{array}\end{array}$ & $0.49^{* * *}$ & 1 & & & \\
$\begin{array}{l}\text { 3. Behavioural } \\
\text { engagement }\end{array}$ & $0.45^{* *}$ & $0.63^{* *}$ & 1 & & \\
$\begin{array}{l}\text { 4. Emotional } \\
\text { engagement }\end{array}$ & $0.49^{* *}$ & $0.71^{* *}$ & $0.58^{* *}$ & 1 & \\
$\begin{array}{l}\text { 5. Cognitive } \\
\text { engagement }\end{array}$ & $0.47^{* * *}$ & $0.69^{* *}$ & $0.52^{* * *}$ & $0.54 * *$ & 1 \\
\hline
\end{tabular}

$\mathrm{N}=266, * * \mathrm{p}<0.01$.

\section{Structural Equation Model Analysis}

First, we established the direct effect model that assessed the relationship between TAS and the three engagement outcomes (behavioural, emotional and cognitive) in one model. The direct model statistics revealed an acceptable fit to the data: $\chi 2=126.92$, $\mathrm{df}=61, \chi 2 / \mathrm{df}$ ratio $=2.08, \mathrm{CFI}=0.94, \mathrm{IFI}=0.95, \mathrm{RMSEA}(90 \% \mathrm{CI})$ $=0.064(0.048-0.080)$, SRMR $=0.06$. The results of the standardized regression revealed that TAS had significant direct prediction on behavioural engagement $(\beta=.79, \mathrm{p}<.001)$, emotional engagement $(\beta=.92, \mathrm{p}<.001)$ and cognitive engagement $(\beta=.79, \mathrm{p}<.001)$.

In the second step, we developed the indirect effect model in which we introduced the construct of PB goals in the model, as 
portrayed in Figure 1. Given the positive significant effect of TAS on students' engagement outcomes, we stated that TAS had an indirect relationship with the engagement outcomes, in which this relation was being mediated by PB goals. The PB goals construct was added into the relationships between TAS and the three aspects of student engagement by adding the path from TAS to PB goals and paths from PB goals to the three engagement outcomes. The full model (direct and indirect) had a good fit to the data as follow: $\chi^{2}=195.88$, $\mathrm{df}=111, \chi 2 / \mathrm{df}$ ratio $=1.76, \mathrm{CFI}=0.95, \mathrm{IFI}=0.95$, RMSEA $(90 \%$ $\mathrm{CI})=0.054(0.048-0.080), \mathrm{SRMR}=0.05$. The full model showed a significantly better fit than the direct model $\Delta \chi^{2}(50)=68.96, \mathrm{p}<$ .05

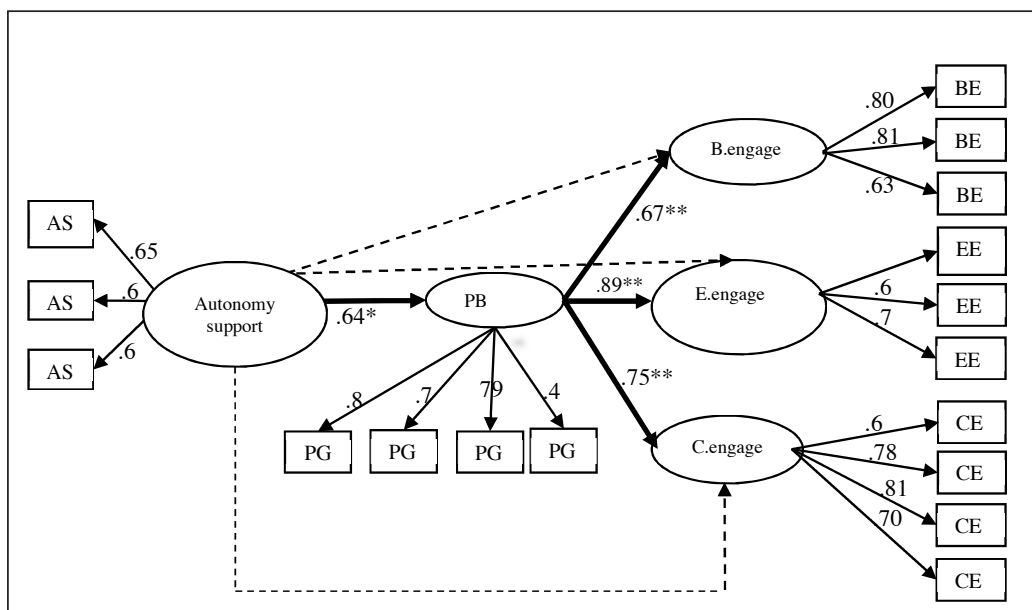

Figure 1. Full model depicting mediational goal effect of PB goals between TAS and student engagement.

Note $: \mathrm{PB}$ goals $=$ personal best goals, $\mathrm{B}$.engage $=$ behavioural engagement, E.engage $=$ emotional engagement, C.engage $=$ cognitive engagement. Dashed lines refer to the non-significant paths. $* * * \mathrm{p}<0.001$.

Finally, the significance levels of indirect effects were tested using the bias-corrected bootstrap approach at $95 \%$ confidence interval level. As shown in Table 3, all the indirect effects were statistically significant which supported our hypothesis concerning the mediating role of PB goals. The results in Table 3 indicate that all the indirect paths from TAS to behavioural $(\beta=.42, \mathrm{p}<.001)$, emotional $(\beta=$ 
$.56, \mathrm{p}<.001)$ and cognitive engagement $(\beta=.47, \mathrm{p}<.001)$ were significant, through the mediation of PB goals. Moreover, with the addition of PB goals, the direct effects of TAS on engagement outcomes became non-significant, indicating there was a full mediating effect of PB goals.

Table 3

Bias-corrected Bootstrap Analyses on the Significance of Mediation

\begin{tabular}{llcc}
\hline Paths & \multirow{2}{*}{$\beta$} & $95 \%$ CI & \\
\cline { 3 - 4 } & & Low & High \\
\hline $\begin{array}{l}\text { Autonomy support- } \\
\text { behavioural engagement }\end{array}$ & 0.191 & -0.032 & 0.413 \\
$\begin{array}{l}\text { Autonomy support- } \\
\text { emotional engagement }\end{array}$ & 0.140 & -0.049 & 0.326 \\
$\begin{array}{l}\text { Autonomy support- } \\
\text { cognitive engagement }\end{array}$ & 0.134 & -0.068 & 0.342 \\
$\begin{array}{l}\text { Autonomy support- } \\
\text { PB goals - behavioural } \\
\text { engagement }\end{array}$ & $0.426 * * *$ & 0.284 & 0.619 \\
$\begin{array}{l}\text { Autonomy support- } \\
\text { PB goals - emotional } \\
\text { engagement }\end{array}$ & $0.567 * * *$ & 0.444 & 0.731 \\
$\begin{array}{l}\text { Autonomy support- } \\
\text { PB goals - cognitive } \\
\text { engagement }\end{array}$ & $0.479 * * *$ & & \\
\hline
\end{tabular}

Note. $\mathrm{PB}$ goals $=$ personal best goals $* * * \mathrm{p}<.001$.

\section{DISCUSSION}

According to SDT, teaching styles that consider students' interests and preferences and facilitate students' volitional endorsement during learning activities would promote autonomous motivation, 
and encourage students to overcome academic challenges and set meaningful learning goals (Jang et al., 2010). These assertions were confirmed in the present study within a sample of undergraduates in Malaysia. Using SEM analysis, two hypotheses were tested: (a) perceived TAS would positively predict student engagement, and (b) PB goals would mediate the relationship between perceived TAS and three aspects of student engagement (cognitive, behavioural and emotional). The two postulated hypotheses regarding the direct and indirect associations among the study variables were supported by the results of the study.

With regards to the importance of contextual factors, a considerable number of studies within SDT have indicated the importance of TAS in predicting positive educational outcomes (e.g., Barreto, Vasconcelos, \& Orey, 2017; Gagné, 2003; Hospel \& Galand, 2016; Jang et al., 2010). In parallel, the current study has revealed that TAS predicted students' cognitive, behavioural and emotional engagement significantly and positively, which indicates that high perceived TAS is relevant to greater student engagement. More precisely, students who experienced more high autonomy-supportive teaching styles responded with greater cognitive, behavioural and emotional engagement in their classes. This finding supports SDT's notion that ideal learning engagement is considered to be a direct product of student's autonomous type of motivation, which can be optimally aroused in autonomy-supportive environments (Reeve, 2012). When students experience TAS, they are more likely to demonstrate more impressive educational outcomes such as student engagement, in comparison to students who experience controlling teaching styles (Jang et al., 2010). In the current study, TAS enhanced students' sense of self-determination, volition, and psychological freedom, which in turn produced students' engagement during their learning activities.

Furthermore, the findings from indirect relationships revealed that the construct of $\mathrm{PB}$ goals has a significant role in explaining the underlying mechanism by which TAS predicts enhanced cognitive, behavioural and emotional engagement. The findings highlighted the importance of PB goals adaption for the improvement of students' engagement within higher education contexts, which is consistent with past findings on students at elementary school level (e.g., Collie et al., 2015; Martin et al., 2016; Martin \& Elliot, 2015). We turn to 
the SDT elements for PB goals to understand why these findings may occur in classroom settings. PB goals are a type of growth goals that are self-created by the students themselves, determined by them, and are self-improvement and self-referenced based goals regarding educational progress and products (Collie et al., 2015). In this sense, PB goals are mainly featured by the self-determination and personalized standards of students; this key feature of PB goals is encouraged by appropriate TAS (Collie et al., 2015; Deci \& Ryan, 2000). As a result, in an autonomy supportive environment, students identify and pursue their goal for autonomous reasons, rather than feeling pressured or compelled to carry out activities for extrinsic reasons. This in turn helps in forming self-referenced goals and predicts better behavioural, cognitive and emotional outcomes.

It is interesting to note that the construct of TAS had a significant relationship with the three types of student engagement which turned out to be non-significant by the inclusion of PB goals, indicating that there was a full mediating effect of PB goals. We can conclude, therefore, that perceived TAS may function more effectively via promoting $\mathrm{PB}$ goals to predict student engagement. It highlights the critical role of a corresponding adoption of personal growth (in terms of PB goals) in explaining the mechanism that underlies the observed relationships between the students' perceived learning environment (in terms of TAS) and students' cognitive, behavioural and emotional engagement.

\section{CONCLUSION}

The current research is among the first to study the relationships of perceived TAS, PB goals and student engagement simultaneously within a sample of Malaysian undergraduate students. Based on SDT assumptions, the results of this study highlight that the relationships between TAS and students' behavioural, emotional, and cognitive engagement are mediated via the potential mechanism of PB goals. In this sense, this study provides critical support regarding the applicability of SDT postulations in terms of TAS and PB goals in higher education learning contexts, and suggests that with the provision of TAS, even in collectivist cultures, students can be encouraged to form student-led goals rather than teacher-led goals. Institutes of higher education in Malaysia must focus on creating learning environments that facilitate self-determined behaviours 
among students. Behaviours such as acknowledging student perspectives, providing them with a rationale for their learning, and allowing self-expression and volition will create conducive environments for students to nurture PB goals and enhance engagement.

Despite noteworthy results, the study is not without limitations. First, it was a cross-sectional study which analysed only the current existing links among the variables and did not consider the causal relationships. Thus, a longitudinal design is warranted to detect the causal associations between the above-mentioned constructs and to be cautious about the role of time in the interpretation of the results. Second, this study assessed students' perceptions about TAS; future studies could measure the perceptions of teachers on their own autonomy support to understand whether they facilitate the nurturance of PB goals among students (e.g., Soenens, Sierens, Vansteenkiste, Dochy, \& Goossens, 2012). Third, the measurement of the constructs was strictly derived from self-report methods. Future studies, therefore, could introduce meaningful qualitative methods such as observations or interviews to gain deeper insights regarding the function of the variables of this research. Furthermore, due to the different culture values which may influence how PB functions, replications of this research in other educational settings and countries should be attempted.

\section{ACKNOWLEDGEMENT}

This research was supported by a Postgraduate Scheme Incentive Research Grant (S/O Code: 16052) awarded by the Awang Had Salleh Graduate School, Universiti Utara Malaysia.

\section{REFERENCES}

Abdul Rahim, F., \& Lee , S. C. (2017). Proposing an affective literacy framework for young learners of English in Malaysian rural areas: Its key dimensions and challenges. Malaysian Journal of Learning and Instruction, 14(2), 115-144.

Abdullah, M. C., Teoh, H., Roslan, S., \& Uli, J. (2015). Student engagement: Concepts, development and application in Malaysian universities. Journal of Educational and Social Research, 5(2), 275-284. 
Ames, C. (1992). Classrooms: Goals, structures, and student motivation. Journal of Educational Psychology, 84(3), 261271.

Assor, A., Kaplan, H., \& Roth, G. (2002). Choice is good, but relevance is excellent: Autonomy-enhancing and suppressing teacher behaviours predicting students' engagement in schoolwork. British Journal of Educational Psychology, 72(2), 261-278.

Awang-Hashim, R., Kaur, A., \& Noman, M. (2015). The interplay of socio-psychological factors on school engagement among early adolescents. Journal of Adolescence, 45, 214-224.

Awang-Hashim, R., \& Sani, A. M. (2008). A comfirmatory factor analysis of a newly integrated multidimensional school engagement scale. Malaysian Journal of Learning \& Instruction, 5, 21-40.

Baron, R. M., \& Kenny, D. A. (1986). The moderator-mediator variable distinction in social psychological research: Conceptual, strategic, and statistical considerations. Journal of Personality and Social Psychology, 51(6), 1173-1184.

Barreto, D., Vasconcelos, L., \& Orey, M. (2017). Motivation and learning engagement through playing math video games. Malaysian Journal of Learning and Instruction, 14(2), 1-21.

Benita, M., Roth, G., \& Deci, E. L. (2014). When are mastery goals more adaptive? It depends on experiences of autonomy support and autonomy. Journal of Educational Psychology, 106(1), 258-267.

Benita, M., Shane, N., Elgali, O., \& Roth, G. (2017). The important role of the context in which achievement goals are adopted: An experimental test. Motivation and Emotion, 41(2), 180195.

Center for Community College Student Engagement (CCCSE). (2019). Why focus on student engagement? Retrieved from http://www.ccsse.org/center/about_cccse/overview.cfm.

Ciani, K. D., Sheldon, K. M., Hilpert, J. C., \& Easter, M. A. (2011). Antecedents and trajectories of achievement goals: A self-determination theory perspective. British Journal of Educational Psychology, 81(2), 223-243.

Collie, R. J., \& Martin, A. J. (2015). Teachers' psychological needs, motivation, and autonomy-support: Impacts on students' growth goals and achievement outcomes. In B. Higgins (Ed.), Goal setting and personal development: Teachers' 
perspectives, behavioral strategies and impacton performance (pp. 1-14). New York: Nova Science Publishers.

Collie, R. J., Martin, A. J., Papworth, B., \& Ginns, P. (2015). Students' interpersonal relationships, personal best (PB) goals, and academic engagement. Learning and Individual Differences, 45, 65-76.

Creswell, J.W. (2012). Educational research: Planning, conducting, and evaluating quantitative and qualitative research (4th ed). Boston: Pearson Education.

Deci, E. L., \& Ryan, R. M. (2000). The "what" and" why" of goal pursuits: Human needs and the self-determination of behavior. Psychological Inquiry, 11(4), 227-268.

Deci, E. L., \& Ryan, R. M. (2008). Self-determination theory: A macrotheory of human motivation, development, and health. Canadian Psychology/Psychologie canadienne, 49(3), 182185.

Elliot,A.J., Murayama, K., \& Pekrun, R.(2011).A $3 \times 2$ achievement goal model. Journal of Educational Psychology, 103(3), 632648.

Fredricks, J., Blumenfeld, P. C., \& Paris, A. H. (2004). School engagement: Potential of the concept, state of the evidence. Review of Educational Research, 74(1), 59-109.

Gagné, M. (2003). The role of autonomy support and autonomy orientation in prosocial behavior engagement. Motivation and Emotion, 27(3), 199-223.

Hair, J., Anderson, R., Tatham, R., \& Black, W. (2006). Multivariate data analysis. (6th ed). New Jersey: Prentice Hall.

Hang, B. T. T., Kaur,A., \& Nur, A. H. B. (2017). A self-determination theory based motivational model on intentions to drop out of vocational schools in Vietnam. Malaysian Journal of Learning and Instruction, 14(1), 1-21.

Hanita, M. Y., \& Azman, N. (2018). Academic achievement among male and female students: the role of learning support and students' engagement. Malaysian Journal of Learning and Instruction, 15(2), 257-287.

Healey, M., Flint, A., \& Harrington, K. (2014). Engagement through partnership: Students as partners in learning and teaching in higher education. New York: Higher Education Academy.

Heng, K. (2014). The relationships between student engagement and the academic achievement of first-year university students in Cambodia. The Asia-Pacific Education Researcher, 23(2), 179-189. 
Hospel, V., \& Galand, B. (2016). Are both classroom autonomy support and structure equally important for students' engagement? A multilevel analysis. Learning and Instruction, 41, 1-10.

Hu, L. T., \& Bentler, P. M. (1999). Cutoff criteria for fit indexes in covariance structure analysis: Conventional criteria versus new alternatives. Structural Equation Modeling: A Multidisciplinary Journal, 6(1), 1-55.

Jang, H., Kim, E. J., \& Reeve, J. (2012). Longitudinal test of selfdetermination theory's motivation mediation model in a naturally occurring classroom context. Journal of Educational Psychology, 104(4), 1175-1188.

Jang, H., Reeve, J., \& Deci, E. L. (2010). Engaging students in learning activities: It is not autonomy support or structure but autonomy support and structure. Journal of Educational Psychology, 102(3), 588-600.

Jang,H.,Reeve, J., \& Halusic, M. (2016). Anew autonomy-supportive way of teaching that increases conceptual learning: Teaching in students' preferred ways. The Journal of Experimental Education, 84(4), 686-701.

Ko, J. W., Park, S., Yu, H. S., Kim, S.-J., \& Kim, D. M. (2016). The structural relationship between student engagement and learning outcomes in Korea. The Asia-Pacific Education Researcher, 25(1), 147-157.

Leech, N. L., Barrett, K. C., \& Morgan, G. A. (2005). SPSS for intermediate statistics: Use and interpretation. New Jersey: Psychology Press.

Little, B., Locke, W., Scesa, A., \& Williams, R. (2009). Report to HEFCE on student engagement. London: Centre for Higher Education Research and Information.

Macfarlane, B., \& Tomlinson, M. (2017). Critiques of student engagement. Higher Education Policy, 30(1), 5-21.

MacKinnon, D. P., Lockwood, C. M., \& Williams, J. (2004). Confidence limits for the indirect effect: Distribution of the product and resampling methods. Multivariate Behavioral Research, 39(1), 99-128.

Maehr, M. L. (2001). Goal theory is not dead-Not yet, anyway: A reflection on the special issue. Educational Psychology Review, 13(2), 177-185.

Maguire, R., Egan, A., Hyland, P., \& Maguire, P. (2016). Engaging students emotionally: The role of emotional intelligence in 
predicting cognitive and affective engagement in higher education. Higher Education Research \& Development, 36(2), 1-15.

Marsh, H. W., Hau, K.-T., \& Wen, Z. (2004). In search of golden rules: Comment on hypothesis-testing approaches to setting cutoff values for fit indexes and dangers in overgeneralizing $\mathrm{Hu}$ and Bentler's (1999) findings. Structural Equation Modeling, 11(3), 320-341.

Martin, A. J. (2012). The role of personal best (PB) goals in the achievement and behavioral engagement of students with ADHD and students without ADHD. Contemporary Educational Psychology, 37(2), 91-105.

Martin, A. J., Collie, R. J., Mok, M. M. C., \& McInerney, D. M. (2016). Personal best (PB) goal structure, individual PB goals, engagement, and achievement: A study of Chinese-and English-speaking background students in Australian schools. British Journal of Educational Psychology, 86(1), 75-91.

Martin, A. J., \& Elliot, A. J. (2015). The role of personal best (PB) and dichotomous achievement goals in students' academic motivation and engagement: A longitudinal investigation. Educational Psychology, 36(7), 1285-1302.

Martin, A. J., \& Liem, G. A. D. (2010). Academic personal bests (PBs), engagement, and achievement: A cross-lagged panel analysis. Learning and Individual Differences, 20(3), 265270.

Md Jaafar, F., Awang-Hashim, R., \& Tengku Ariffin, T. F. (2012). Malaysian university student learning involvement scale (MUSLIS): Validation of a student engagement model. Malaysian Journal of Learning and Instruction, 9, 15-30.

Ministry of Higher Education. (2016). Malaysia Education Blueprint 2015-2025 (Higher Education). Retrieved from https://www. mohe.gov.my/en/download/public/penerbitan/pppm-20152025-pt/5-malaysia-education-blueprint-2015-2025-highereducation

Niemiec, C. P., \& Ryan, R. M. (2009). Autonomy, competence, and relatedness in the classroom: Applying self-determination theory to educational practice. School Field, 7(2), 133-144.

Núñez, J. L., \& León, J. (2019). Determinants of classroom engagement: A prospective test based on self-determination theory. Teachers and Teaching, 25(2), 147-159.

Reeve, J. (2006). Teachers as facilitators: What autonomy-supportive teachers do and why their students benefit. The Elementary School Journal, 106(3), 225-236. 
Reeve, J. (2009). Why teachers adopt a controlling motivating style toward students and how they can become more autonomy supportive. Educational Psychologist, 44(3), 159-175.

Reeve, J. (2012). A self-determination theory perspective on student engagement. In A. L. R. S. L. Christenson, \& C. Wylie (Ed.), Handbook of research on student engagement (pp. 149-172). New York: Springer.

Reeve, J. (2013). How students create motivationally supportive learning environments for themselves: The concept of agentic engagement. Journal of Educational Psychology, 105(3), 579-595.

Reeve, J., \& Halusic, M. (2009). How K-12 teachers can put selfdetermination theory principles into practice. School Field, 7(2), 145-154.

Ryan, R. M., \& Deci, E. L. (2000). Self-determination theory and the facilitation of intrinsic motivation, social development, and well-being. American Psychologist, 55(1), 68-78.

Sahil, S. A. S., \& Awang-Hashim, R. (2011). The roles of social support in promoting adolescent's classroom cognitive engagement through academic self-efficacy. Malaysian Journal of Learning and Instruction, 8, 49-69.

Salleh, A. M., Desa, M. M., \& Tuit, R. M. (2013). The relationship between the learning ecology system and students' engagement: A case study in Selangor. Asian Social Science, 9(12), 110-117.

Skinner, E.A., Kindermann, T. A., \& Furrer, C. J. (2009). A motivational perspective on engagement and disaffection: Conceptualization and assessment of children's behavioral and emotional participation in academic activities in the classroom. Educational and Psychological Measurement, 69(3), 493-525.

Soenens, B., Sierens, E., Vansteenkiste, M., Dochy, F., \& Goossens, L. (2012). Psychologically controlling teaching: Examining outcomes, antecedents, and mediators. Journal of Educational Psychology, 104(1), 108-120.

Trowler, V., \& Trowler, P. (2010). Student engagement case studies Deliverable 3 for the higher education academy student engagement project. York: Higher Education Academy.

Vansteenkiste, M., Lens, W., Elliot, A. J., Soenens, B., \& Mouratidis, A. (2014). Moving the achievement goal approach one step forward: Toward a systematic examination of the autonomous 
and controlled reasons underlying achievement goals. Educational Psychologist, 49(3), 153-174.

Williams, G. C., \& Deci, E. L. (1996). Internalization of biopsychosocial values by medical students: a test of selfdetermination theory. Journal of Personality and Social Psychology, 70(4), 767-779.

Wolters, C. A. (2004). Advancing achievement goal theory: Using goal structures and goal orientations to predict students' motivation, cognition, and achievement. Journal of Educational Psychology, 96(2), 236-250.

$\mathrm{Yu}, \&$ Martin,A.J.(2014).Personalbest(PB) and 'classic'achievement goals in the Chinese context: Their role in predicting academic motivation, engagement and buoyancy. Educational Psychology, 34(5), 635-658.

Yuan, J., \& Kim, C. (2018). The effects of autonomy support on student engagement in peer assessment. Educational Technology Research and Development, 66(1), 25-52.

Yusoff, N. M. (2012). Student engagement at the higher learning institutions: The case of Malaysia and the United Arab Emirates. Aceh International Journal of Social Science, 1(1), $1-11$.

Zepke, N. (2017). Student engagement in neoliberal times: Theories and practices for learning and teaching in higher education: Singapore: Springer Nature Singapore. 